\title{
Research on the Framework of the Construction of Financial Management Informatization
}

Dai Yuanjun

Guangzhou Civil Aviation College

Abstract: The development of our country's financial industry can not do without new information technology. In this information age, all industries require the application of information technology. The arrival of the information age not only affects human life, but also promotes the effective development of economy and brings a lot of help to the development of financial economy. The imperfect construction of financial information management leads to a series of problems, which limits the progress of the construction of financial informatization. This article briefly introduces the current situation and existing problems of the construction of financial management informatization, puts forward reasonable and effective solving strategies to promote our country's construction of financial management informatization.

Keywords: financial institutions, deficiencies, construction standard, solving strategies

Published Date: January 2018

Published Online: $31^{\text {st }}$ January 2018

Corresponding Author: Dai Yuanju, Guangzhou Civil

Aviation College, No. 10th Xiangyunxi Street, Jichang Road, Baiyun District, Guangzhou, Guangdong Province,

276712921@qq.com

\section{Introduction}

Scholars hold different views on how to define financial management informatization. Some scholars think that its essence is to apply various information technologies to financial industry, while some think it is an innovative financial management mode. Strengthening the construction of the framework of financial management informatization is one of the most effective ways to improve the effectiveness of financial management. The way of construction is diversified. This article conducts in- depth and objective research, of which the result is shared with managers of financial industry.

1 The construction of the framework is the foundation of realizing financial management informatization

Financial management informatization means with the assistance of financial service processing system, managers of financial management department rationally and scientifically apply communication technology and network technology to complete work like transmitting financial management documents, collecting information, detecting and predicting financial risks, evaluating risk index, and automated processing. It can be regarded as an effective way to achieve the full application of all kinds of data information in every link of financial management process. In addition, the construction of the framework of financial management informatization includes various components of financial system. The main components are financial institutions, financial markets and financial infrastructure. Financial institutions can be divided into two major branches, namely, commercial banks and policy banks. Financial markets are the economic markets where currency and financial derivatives are in place. Financial infrastructure generally includes payment, liquidation and accounting systems.

In short, the framework of financial management informatization is the integration of all the above factors. It clearly and completely presents all kinds of internal detection indexes of financial management to managers of the industry. These indexes include financial development index, liquidity indicators, 
profitability index, risk condition index and credit status index. The author holds the view that the construction of the framework of financial management informatization relies greatly on the system of financial management informatization. Therefore, only the system is highly scientific and complete can the framework of financial management informatization adjust and improve the concept and form of financial management, which fully manifests the practicality of the framework of the construction of financial management informatization.

\section{The main functions of the informatization construction of financial management}

\subsection{Enhancing the supervision and achieving the standardized development of enterprises}

When an enterprise is under informatization construction, it requires related personnel of financial enterprises to use the latest information technology to get the information of production and operation, getting the picture of all kinds of problems that might come up in the process, especially some details. The enterprise, therefore, can carry out a comprehensive review of some unexpected events through information technology and ensure to take corresponding measures as soon as possible. It also guarantees the decision makers operate the enterprise from an overall perspective and form the supervision mechanism, which will speed up the development of the enterprise.

\subsection{Allocating resources reasonably}

Nowadays, economic globalization has become the mainstream direction of economic development. Many enterprises start to carry out trans-regional management, which is also the trend of enterprise development. Generally speaking, trans-regional management has many difficulties and risks. Therefore, informatization construction is an inevitable choice for its development. It can combine enterprises in different regions organically, overcome the difficulties caused by distance, and ensure managers to take complete control of enterprise development.

\subsection{Boosting the strength and the overall competitiveness of financial industry}

At present, the economic development of our country is showing an upward trend, but it's still facing great pressure as a whole. With the development of economic globalization and regional integration, the economic market of our country and even the whole world has experienced abnormal fluctuations, and the competitive pressure is soaring. Under such a disturbing circumstance, the key to the success of an enterprise must be its core competitiveness. The most important thing for financial enterprises to develop more adequately and enhance its competitiveness is to realize the informatization construction. The realization of informatization construction in financial management can let enterprises adapt to the current competitive environment in a faster and better way, accelerate the change of management mode, and ensure that their development keeps pace with current social process, so as to achieve more considerable economic benefits and realize the development and prosperity of our economy.

\section{The actual situation of the informatization construction of our country's financial management}

In order to carry out the framework construction of the financial management informatization, the application of various information technologies is quite necessary and feasible, which is actually the adjustment and improvement of the current situation of financial management. The most frequently-used information technologies are computer technology, network technology and multimedia technology. The application of these technologies increases the efficiency of the construction and enhances their own application value.

Many financial industries in our country have actively applied those information technologies and achieved gratifying results, especially in the field of hardware informatization construction, which is mainly because the information technologies can improve 
and upgrade the computer and the network system involved in financial management, as well as organizing and merging financial information resources. Based on that, the basic financial informatization system is created smoothly and effectively. The efficiency of financial management work has also been enhanced. In fact, no matter for the internal financial industry, or for its headquarters or branches, the realization of hardware informatization maximizes the using effect of information technologies like computer, gives financial industry a better development space, trains and exercises the information personnel at the same time.

However, we must clearly recognize that though elusive, some problems do exist. For example, the setting of the application standard of informatization has some significant problems in the process of financial management informatization. Exploring deeply, we'll find that many problems about unclear concepts are long-standing, which brings a great obstacle to the framework construction of financial management informatization. Furthermore, the security of financial resources should also be regarded as one of the key issues, to which managers of financial industry attach great importance. Once there is a problem in it, the framework construction of financial management informatization will be disturbed. It will also bring some economic losses to financial industry and damage its social image.

\section{Continuing to strengthen staff training in financial management work}

\subsection{Conducting systematic knowledge training for each staff member}

In order to strengthen the construction of financial informatization in our country and meet the current demands of market economy development, financial enterprises need to conduct awareness training for the staff. Only the subconsciousness of them is strengthened can they be conscious of informatization management when working. In addition, a complete and systematic knowledge training for each staff member is necessary so that they can normally use and establish the information management platform at work. Managers are supposed to have a general idea of each staff member's theoretical knowledge reserve and practical operation ability, because only when the staff have profound professional knowledge and excellent practical ability, can the information platform keep professional and the integrity of economic development data and related information be enhanced. Professional training for the staff is the first step to establish a professional platform of financial management informatization.

\subsection{Reinforcing the management of administrative personnel and making a perfect working system}

Except for the professional training for the staff, in order to establish the platform of financial management informatization, financial enterprises also need to guarantee staff's ability to work. Only excellent personal ability of the staff can ensure the high level of financial management and the correctness of the results. In addition, it is necessary to continuously improve the professional ability and personal quality of the staff, which is the foundation of the informatization construction of financial management. Based on that, the collection of information can be reasonable and accurate. What's more, financial enterprises should establish a sound information management system, which is the key to the development of each enterprise. The process and requirements of the work and the integrity of the content should be specified in the system, as well as responsibility standards and work specification, so as to ensure that different problems encountered at work have different special personnel to solve.

\section{The aspects that should be paid attention to in the operation of financial management system}

5.1 At present, financial management is based on information with the development of the information age and the improvement of information technology. In the process, some relevant organizations are cut, as well as corresponding levels of organization and 
administrative personnel. The flat structure of financial management can reduce the consumption of administration, improve the speed of information transmission, and then shorten the "information chain". Therefore, it is necessary to set up information-based posts in the structure of financial organization.

5.2 In the financial management system and its operating mechanism, it's necessary to consider the characteristics of the information management and follow the rules and regulations in order to ensure the reform of financial management system. In addition, managers are supposed to frequently encourage financial workers in both spiritual and material terms, so that their professional ability and the quality of the service can be improved. The system of financial management should be innovated unceasingly, but it must be executable and stay fair and impartial when being implemented.

5.3 Financial management should be continuously innovated, the premise of which is the cultivation and absorption of talents. What need to be realized is that a financial management system with a team of creative talents who can think actively is the system conforming to the information age. Due to the development of the age and the wide application of information technology, the management mode of financial management is constantly updated. For example, the financial information in the previous was static and the evaluation was conducted afterward, but owing to the wider financial resources channel, it is now dynamic and its state can be reflected in real time. In addition, the extensive application of financial information technology has brought the corresponding advantages, especially in terms of work. It not only improves work efficiency, but also realizes the effective use and sharing of financial resources, which overcomes the difficulties in resource sharing and improve the quality of work. It also makes great progress in innovating financial management mode. At present, the fusion of sensing technology, communication technology, and computer technology can automatically produce, store, process and control various complicated financial information multi-directionally with high speed. It can provide three-dimensional and well- organized information to the users, thus promoting the development of innovative financial management mode.

5.4 The application of information technology should be improved through proper ways. In order to realize the information sharing of financial resources, the boundaries among financial software need to be broke first. Financial enterprises should use the event-driven method to realize the financial business process re-engineering. It is a short and fast way to deliver financial data and can meet the demands of both management and managers. All the data is collected into a database that can be shared. Therefore, managers at all levels can obtain necessary information in real time dynamically, then making decisions.

\section{Conclusion}

In a word, the construction of financial information management in our country is a big project, also a very complicated and systematic one. The construction of financial informatization is now under reform. Facing all kinds of pressure, the staff and related organizations must stay calm without panic. The success of informatization construction relies on talents and the management philosophy complying with the new era. An innovative financial management philosophy is conducive to the smooth development of information technology. Of course, what current financial information management needs is to innovate management operation system in a correct way. In order to promote the effective development of China's financial management mode, at present, in addition to the issue of information technology, China should also make corresponding changes in appropriate time to realize the greatleap-forward development.

\section{References}

[1] Yinzexi, Shi Guifen. Construction Strategy of Enterprise Internal Control Framework in Informatization Environment[J]. Journal of Beihua University (Social Sciences), 2016, 17(06):113-116.

[2] Sun Tao. Research on Informatization Construction of Financial Management[J]. Manager 
Journal, 2017(01):124.

[3] Liu Siyuan. Analysis on the Framework of the Informatization Construction of Group Foreign Affairs Management and its Benefit[J]. Hubei Electric Power, 2016, 40(S1):20-22+27.

[4] Jin Fang. Demand Analysis and Framework Exploration of the Construction of Information Management System of Scientific Research ProjectTaking an Enterprise as an Example[J]. Commercial
Accounting, 2017(09):97-98.

[5] Li Juan. Study on Informatization Construction of Financial Management in Financial Enterprises[J]. Accounting Learning, 2016(12):56.

[6] Liu Sha. Research on the Framework Construction and Construction Approaches of Financial Management Informatization[J]. Market Modernization, 2016(25):256-257. 